\title{
PENGEMBANGAN BUKU POP-UP KULINER SEBAGAI UPAYA PROMOSI WISATA KULINER KOTA PEKALONGAN
}

\author{
Anisha Alfaticha*, Sari Utari, Habibatus Salimah, Inayatul Ulya \\ Pendidikan Bahasa Inggris \& Pendidikan Matematika \\ Fakultas Keguruan dan Ilmu Pendidikan Universitas Pekalongan
}

Korespondensi: anishaalfa@gmail.com

\begin{abstract}
The promotion which was done by the owner of culinary tourism included $10 \%$ using radio, $20 \%$ private television, $10 \%$ social media, and $60 \%$ no promotion. Knowing this condition, in this research the researchers aimed to develop pop-up book as media to promote Pekalongan culinary. This research used Research and Development design. It was done in 9 Pekalongan culinary tourist resort, they are Warung Mbak Ibah Sorogenen, Pak Bon Sorogenen, Kopi Tahlil Pak Usman, Garang Asem Masduki, Sekoteng Pak Woh, Tauto Bang Dul dan Rohmani, Mie So Krapyak, Oriental Nyonya Silhuet, Gulai Kacang Ijo Pak Boy dan Pak Leman, Es Durian Merak dan Keripik Tahu Pusat Oleh-Oleh Pekalongan. The researchers did exploration to get the information of culinary menus and their history from the owner, next it was continued by making design and prototype. After that, the prototype was validated by the head of Tourism, Culture, Youth, and Sport Ministry. After doing the revision, the product of “Jelajah Kuliner Kota Pekalongan' pop-up books were printed and published. The researchers gave recommendation to the Pekalongan government to use this pop-up book in introducing Pekalongan culinary to students and societies. In addition, this pop-up book can be used as media in promoting Pekalongan culinary through annual exhibitions.
\end{abstract}

Keyword: Development, Pop-up, Tourism, Culinary

\section{PENDAhuluan}

Indonesia merupakan Negara Kepulauan terbesar di dunia yang terletak di Asia Tenggara. Indonesia memiliki beranekaragam budaya dari Sabang sampai Merauke. Keberagaman tersebut merupakan sumber dari kepariwisataan dan berpotensi sebagai daya tarik pariwisata. Pariwisata menjadi sektor yang paling sering diminati oleh wisatawan, baik dari dalam negeri maupun luar negeri. Pariwisata tersebut digunakan sebagai sumber devisa negara dan meningkatkan pendapatan kota maupun provinsi. Salah satu jenis wisata yang sering diminati oleh wisatawan adalah wisata kuliner. Setiap daerah memiliki kuliner khasnya masing-masing seperti halnya Pekalongan. Pekalongan memiliki banyak kuliner khas seperti Nasi Megono, Pindang Tetel, Tauto, Kopi Tahlil, Garang Asem dan lain-lain. Untuk itu, keberadaan wisata kuliner Kota Pekalongan perlu untuk dipublikasikan kepada khalyak.

Untuk mengembangkan wisata kuliner di Pekalongan, perlu adanya promosi yang lebih menarik daripada sebuah ilustrasi gambar saja. Salah satu promosi agar kuliner Pekalongan lebih dikenal oleh masyarakat luas adalah dengan menggunakan media pop up. Pop up adalah sebuah buku yang memiliki unsur tiga dimensi serta memberikan visualisasi yang menarik, mulai dari tampilan gambar yang dapat bergerak ketika halamannya dibuka (Dzuanda,2011:1). Muktiono (2003: 65), buku Pop Up adalah sebuah buku yang memiliki tampilan gambar yang bisa ditegakkan serta membentuk obyekobyek yang indah dan dapat bergerak atau memberi efek yang menakjubkan. Dengan media tersebut, orang-orang cenderung tertarik akan visualisasi gambar yang diberikan, 
sehingga memungkinkan wisata kuliner di Pekalongan menjadi lebih dikenal oleh masyarakat luar.

Tujuan dari penelitian ini adalah mengembangkan buku pop-up sebagai media promosi wisata kuliner Kota Pekalongan. Diharapkan penelitian ini dapat memberikan manfaat dalam mengembangkan wisata kuliner di Kota Pekalongan, meningkatkan keadaan ekonomi para penggelut usaha kuliner di Kota Pekalongan, mengenalkan kuliner khas Pekalongan kepada masyarakat luas.

\section{KAJIAN PUSTAKA}

Peneliti mengkaji 2 penelitian yang telah dilakukan oleh peneliti sebelumnya. Penelitian pertama dilakukan oleh Afrinar Pramitasari (2015) dengan judul Pengembangan buku pop-up Pekalongan: The Word City of Batik sebagai media edumotik Kota Pekalongan Penelitian ini bertujuan untuk mengembangkan buku pop-up sebagai alternatif bahan ajar di sekolah serta mengembangkan potensi industri batik di Kota Pekalongan. Tujuan khusus penelitian adalah 1) mendeskripsikan kondisi Kota Pekalongan berkenaan dengan kebutuhan pengembangan buku pop-up Pekalongan sebagai media edumotik Kota Pekalongan; 2) mendeskripsikan pengembangan buku pop-up Pekalongan: The Word City of Batik sebagai media edumotik Kota Pekalongan. Hasil penelitian menunjukkan belum ada bahan bacaan tentang batik Pekalongan yang didesain khusus untuk anak-anak serta kurangnya pemahaman tentang batik karena belum ada buku bacaan yang atraktif.

Penelitian yang kedua yaitu dilakukan oleh Nizar Zulmi (2018) dengan judul "Reaktualisasi Citra Wisata Kabupaten Batang Melalui Pengembangan Pop-Up Visit Batang Heaven Of Asia Sebagai Media Edumowisata (Edukasi Promosi Wisata) Kabupaten Batang". Penelitian ini bertujuan untuk mengembangkan produk berupa buku Pop-up Visit Batang Heaven of Asia yang mengenalkan potensi pariwisata di Kabupaten Batang. Hasil penelitian tersebut adalah sebuah produk buku pop-up sebagai media edumowisata yang mampu memperlihatkan keunggulan wisata di Kabupaten Batang.

Pada penelitian yang dilakukan oleh para peneliti di atas, Afrinar mengembangkan pop-up sebagai media edukasi batik kepada siswa, sedangkan Nizar mengembangkan popup sebagai edukasi promosi wisata Kabupaten Batang. Berdasarkan 2 penelitian tersebut dapat diketahui bahwa pop-up dapat digunakan untuk media edukasi batik dan edukasi promosi wisata. Oleh karena itu, peneliti tertarik mengembangkan pop-up, namun berbeda dari penelitian terdahulu, pop-up digunakan sebagai media pengenalan wisata kuliner Kota Pekalongan.

\section{METODE}

Penelitian ini menggunakan metode penelitian pengembangan (Research and Development). Metode penelitian dan pengembangan dapat diartikan sebagai cara ilmiah untuk meneliti, merancang, memproduksi dan menguji validitas produk yang telah dihasilkan (Sugiyono, 2016: 30). Tujuan penelitian ini untuk mengembangkan produk berupa buku pop up tentang kuliner Kota Pekalongan.

Penelitian ini dilakukan di tempat-tempat kuliner di Kota Pekalongan, yaitu: Warung Mbak Ibah Sorogenen, Pak Bon Sorogenen, Kopi Tahlil Pak Usman, Garang Asem Masduki, Sekoteng Pak Woh, Tauto Bang Dul dan Rohmani, Mie So Krapyak, Oriental Nyonya Silhuet, Gulai Kacang Ijo Pak Boy dan Pak Leman, Es Durian Merak dan 
Keripik Tahu Pusat Oleh-Oleh Pekalongan. Adapun pelaksanaan kegiatan dilaksanakan selama 5 bulan mulai dari bulan April-Agustus 2019.

Penelitian ini dilakukan dengan beberapa tahapan sebagai berikut:

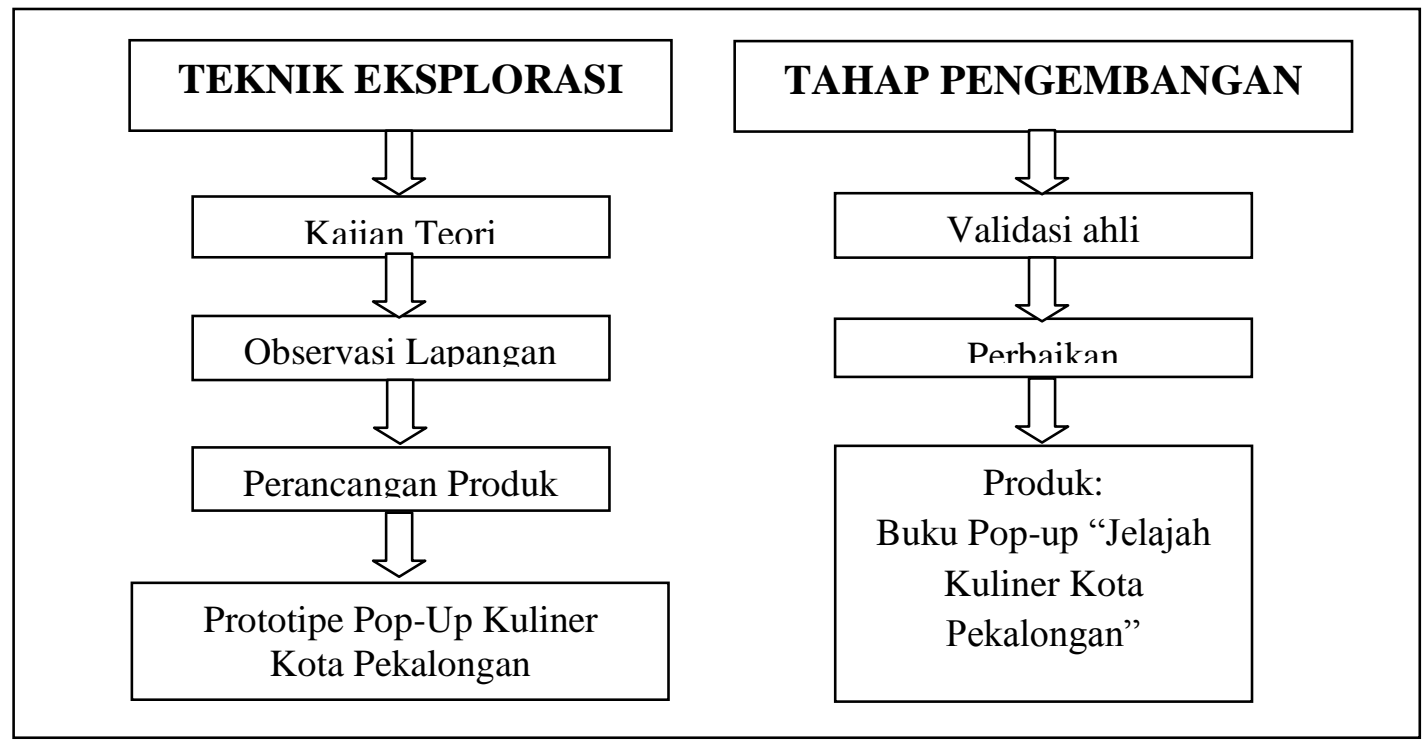

Gambar 1 Bagan Tahapan penelitian

\section{HASIL DAN PEMBAHASAN}

Ada beberapa cara untuk mempromosikan wisata kuliner, yaitu dengan menggunakan iklan di televisi, radio maupun sosial media. Di Kota Pekalongan terdapat banyak wisata kuliner yang perlu dikenalkan kepada masyarakat luas. Sesuai penelitian yang peneliti lakukan, $10 \%$ menggunakan radio, 20\% menggunakan tv swasta, $10 \%$ menggunakan sosial media dan $60 \%$ belum ada media promosi yang digunakan untuk mempromosikan kuliner mereka. Oleh karena itu, peneliti memberi alternatif yaitu dengan menggunakan Buku Pop-Up Jelajah Kuliner Kota Pekalongan.

Penelitian ini dilakukan dalam beberapa tahapan, di antaranya tahap eksplorasi dan tahap pengembangan.

\subsection{Tahap eksplorasi}

1) Observasi lapangan

Pada tahap ini peneliti melakukan kegiatan observasi ke tempat-tempat kuliner yang ada di Kota Pekalongan. Lokasi yang dikunjungi antara lain: Warung Mbak Ibah Sorogenen, Pak Bon Sorogenen, Kopi Thalil Pak Usman, Garang Asem Masduki, Tauto Bang Dul dan Rohmani, Mie So Krapyah, Oriental Nyonya Silhuet, Gulai Kacang Ijo Pak Boy dan Pak Leman, Es Durian Merak, dan Keripik Tahu Pusat Oleh-Oleh Pekalongan. Pada langkah ini peneliti melakukan wawancara terhadap pemilik warung mengenai makanan khas dan sedikit sejarah mengenai makanan tersebut.

2) Perancangan

Pada tahap selanjutnya peneliti melakukan perancangan pembuatan pop-up yaitu dengan membuat desai terlebih dahulu di kertas, kemudian diterapkan pada aplikasi CorelDraw x7. 


\subsection{Tahap Pengembangan}

1) Validasi

Dalam tahap ini, penelitian mengajukan permohonan validasi prototype buku pop-up kuliner kepada Kepala Dinparbudpora Kota Pekalongan. Validasi dilakukan terhadap cover hingga konten buku pop-up. Validasi dilakukan oleh Kepala Dinparbudpora Kota Pekalongan, Bapak Sutarno, S.H., MM. Berikut ini saran dan masukan yang diberikan pada saat velidasi, di antaranya:

a) Pada sampul buku, perlu ditambahkan nama penulis (mahasiswa dan dosen pemdamping).

b) Tambahkan logo Kota Pekalongan.

c) Tambahkan kata pengantar dari Dinparbudpora Kota Pekalongan.

d) Tambahkan alamat-alamat lokasi kuliner

e) Tambahkan daftar isi dan halaman.

f) Latar belakang halaman buku diberi gambar Batik.

g) Tambahkan slogan Kota Pekalongan 'The World City of Batik'

h) Tambahkan daftar pustaka.

2) Perbaikan

Setelah dilakukan vaslidasi oleh Kepala Dinparbudpora Kota Pekalongan, kemudian peneliti melakukan perbaikan pada pop-up tersebut sebelum dipublikasikan kepada masyarakat Kota Pekalongan. Berikut adalah gambar desain pop-up setelah perbaikan:

a) Sampul

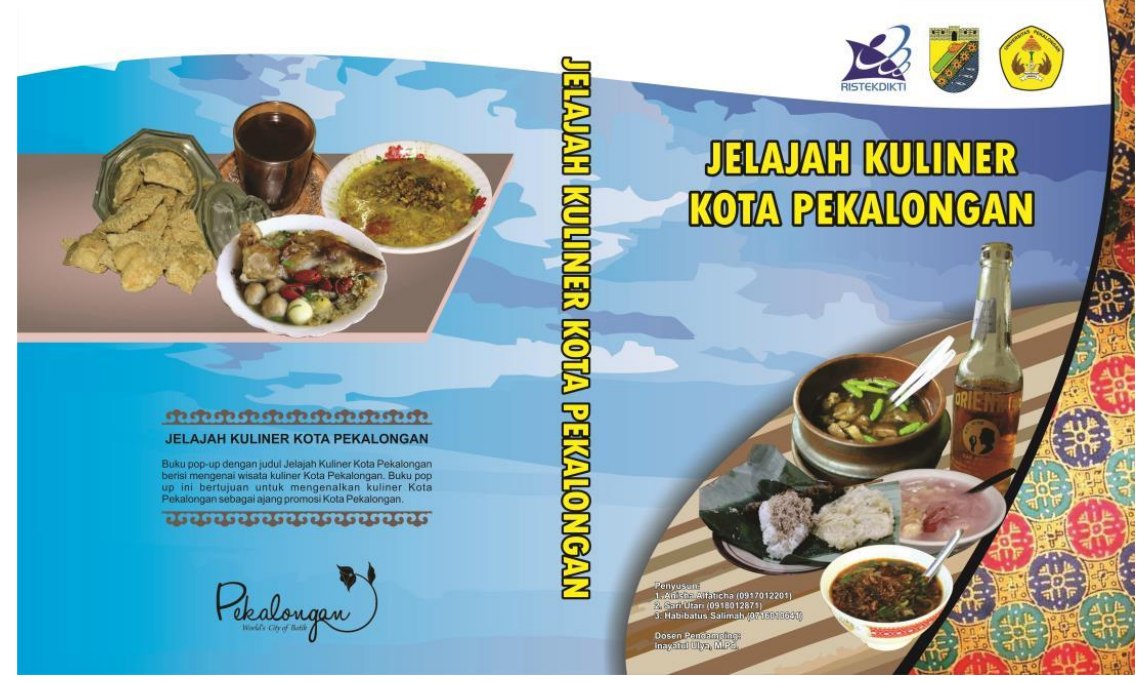

Gambar 2 Sampul

Pada sampul ditambahkan nama tim peneliti dan dosen pendamping, selain itu gambar batik diganti dengan motif batik khas Pekalongan (Jlamprang). Sedangkan pada cover belakang ditambahkan slogan Pekalongan "The world city of Batik".

b) Kata Pengantar, Prakata dan Daftar Isi

Pada prototype 1 pop-up dibuka dengan pendahuluan, setelah diperbaiki menjadi redaksi kata pengantar dan prakata. Selain itu, Pada prototype awal tidak terdapat daftar isi, setelah diberi masukan oleh validator maka ditambahkan daftar isi agar mempermudah pencarian halaman. 


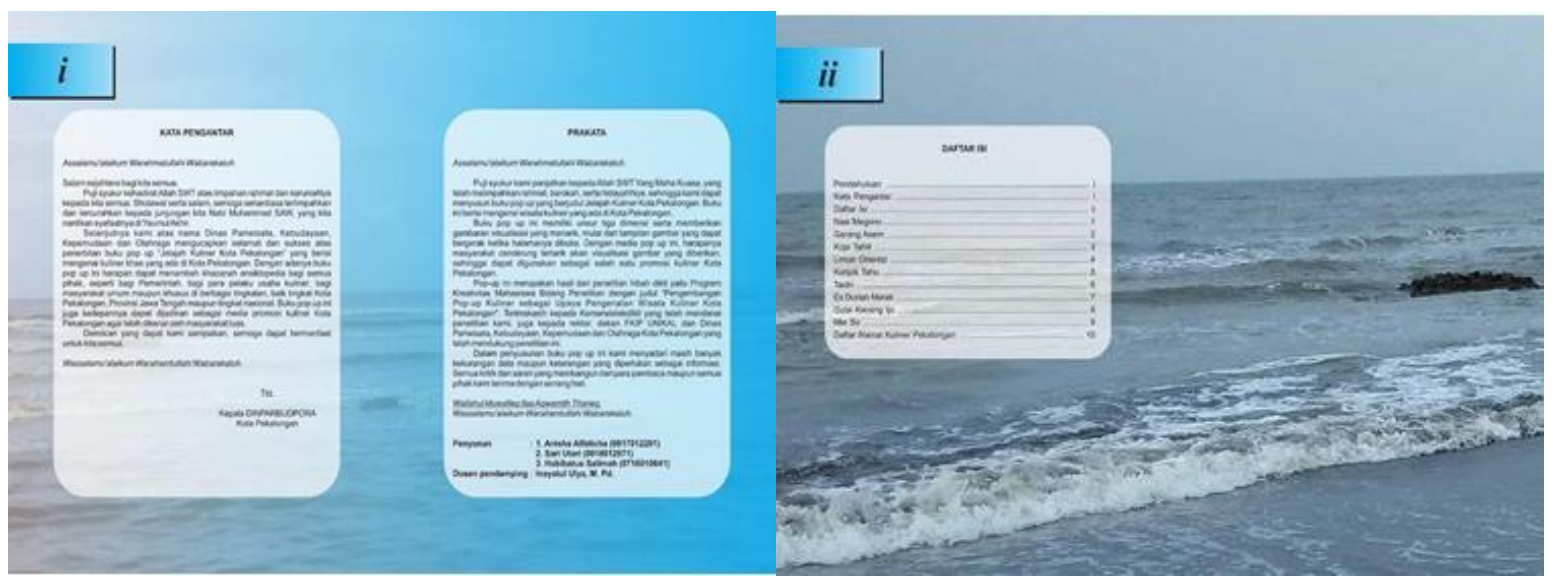

Gambar 3 Prakata dan Daftar Isi

c) Penambahan batik pada latar belakang halaman isi buku

Desain motif kain bercorak kotak-kotak di bawah makanan pada setiap halaman diperbaiki dengan desain motif batik pada sisi kiri dan kanan halaman untuk mencirikan Kota Pekalongan. Selain itu, ditambahkan nomer halaman untuk mempermudah pencarian.

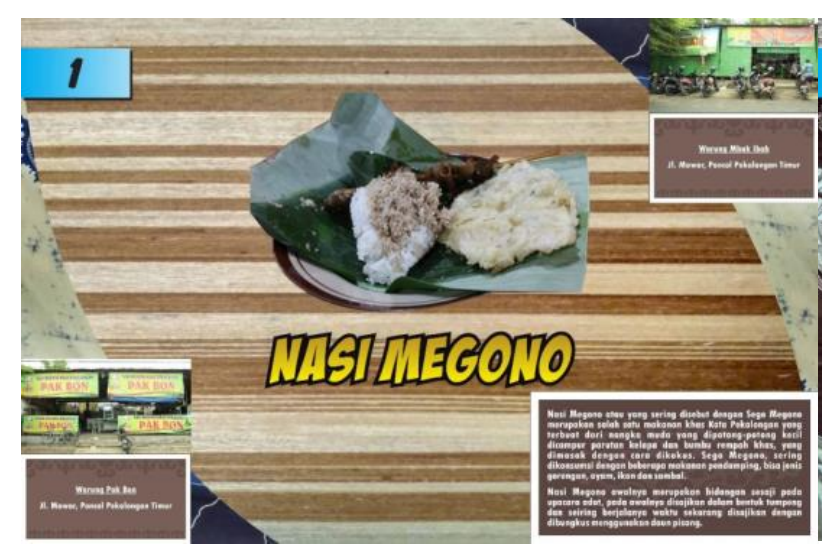

Gambar 4 Nasi Megono

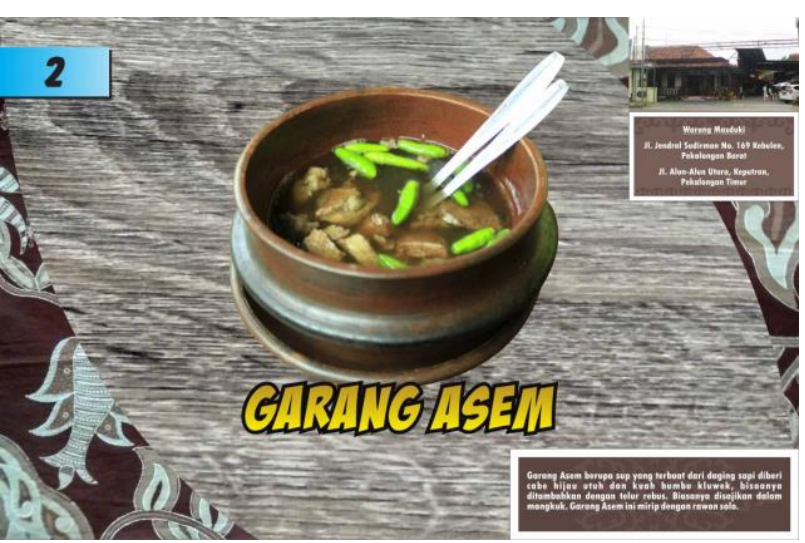

Gambar 5 Garang Asem

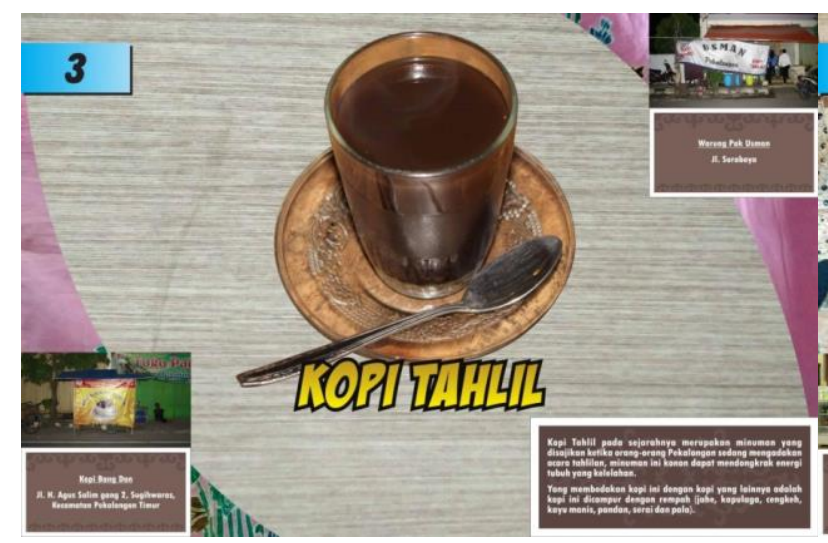

Gambar 6 Kopi Tahlil

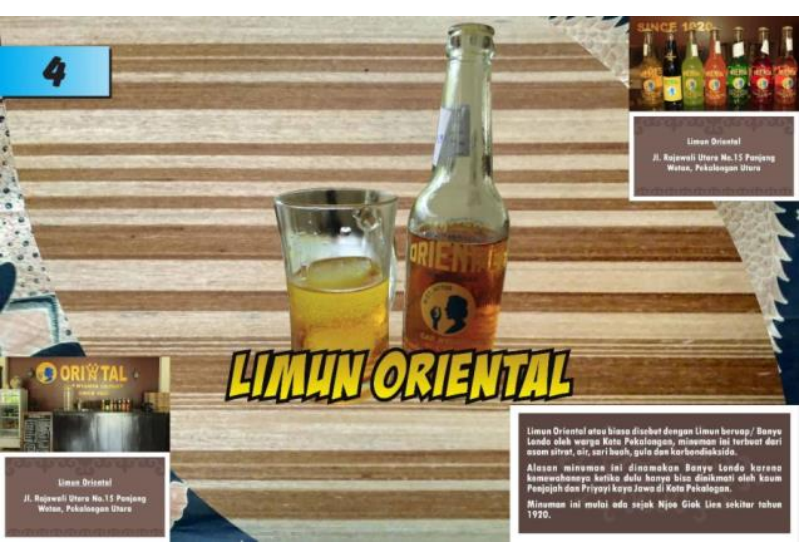

Gambar 7 Limun Oriental 

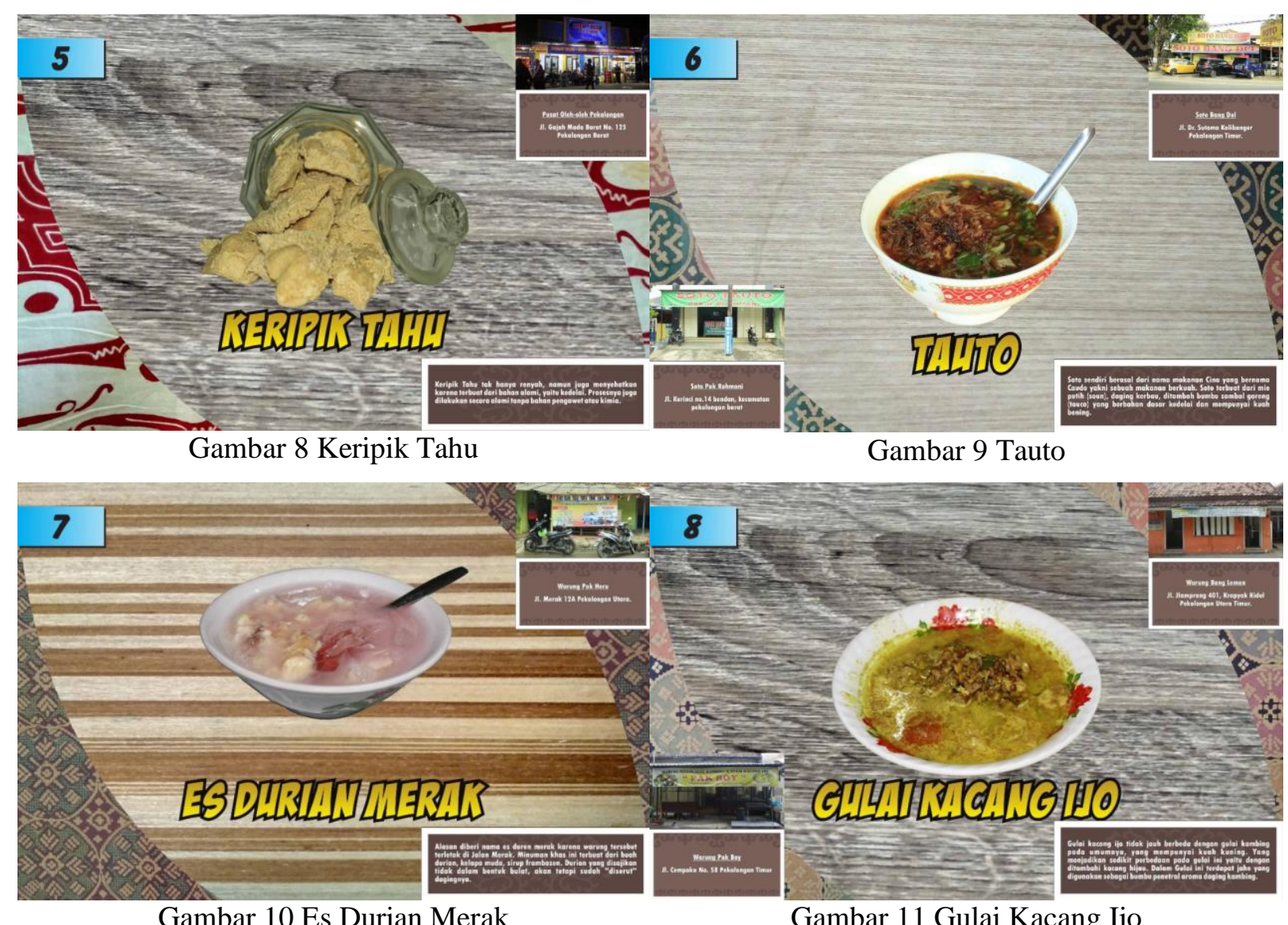

Gambar 10 Es Durian Merak

Gambar 11 Gulai Kacang Ijo

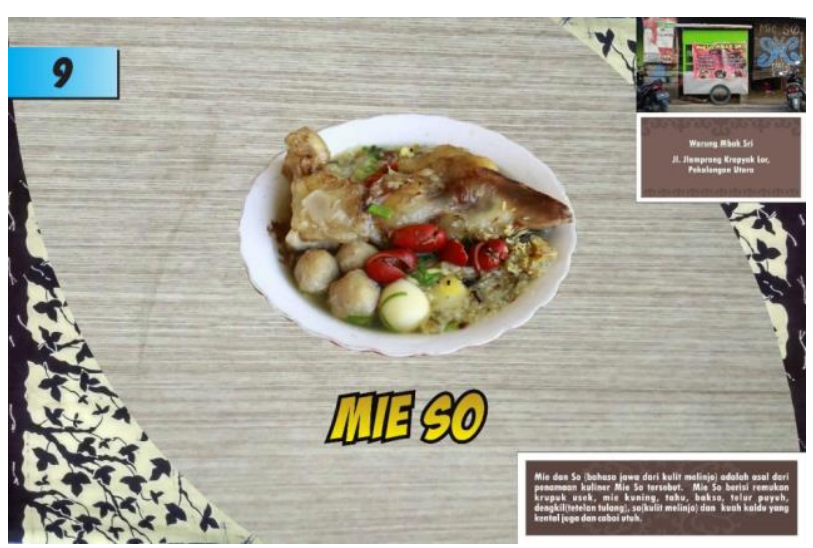

Gambar 12 Mie So

d) Alamat lokasi wisata kuliner

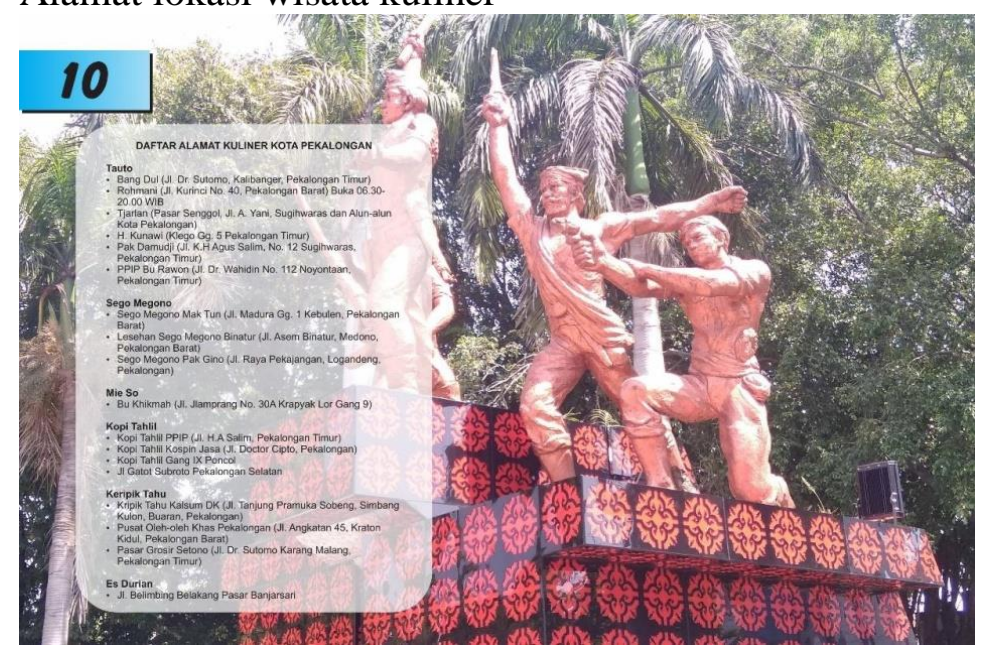

Gambar 13 Daftar Alamat Kuliner Kota Pekalongan 
e) Halaman Akhir

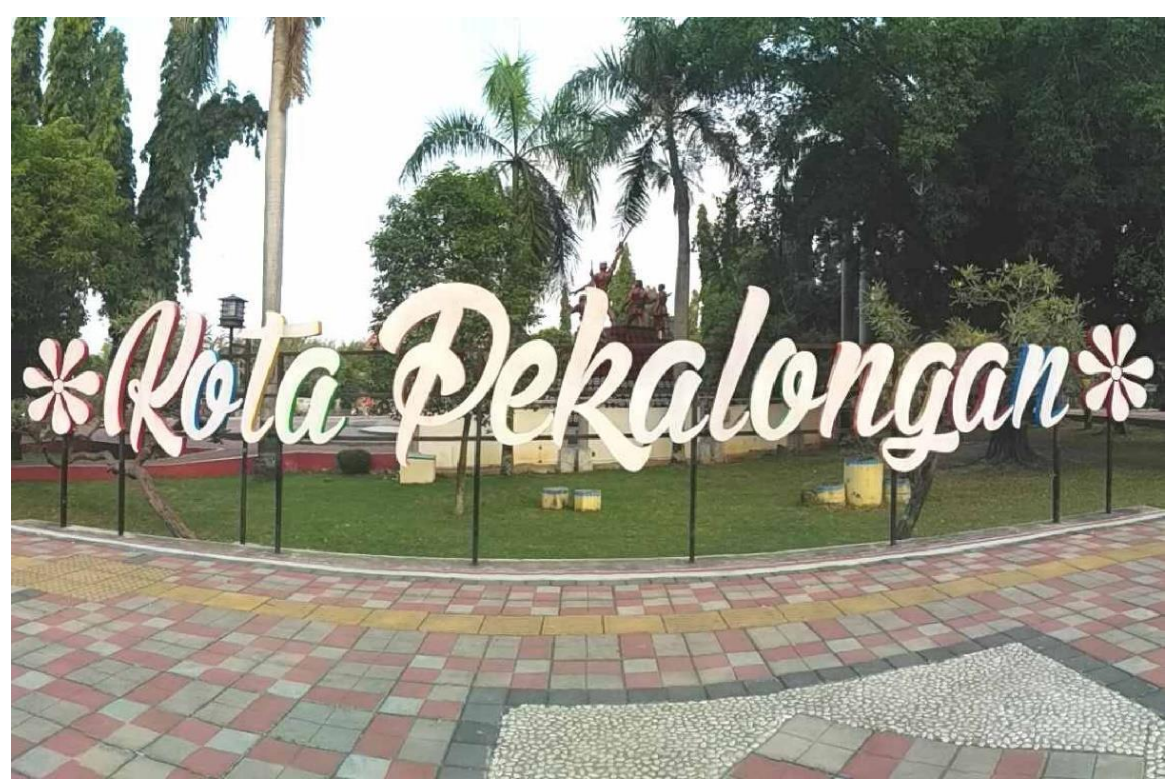

Gambar 14 Ikon Kota Pekalongan Pekalongan".

Pada bagian akhir ditambahkan latar belakang ikon tulisan "Kota

Dari desain gambar tersebut kemudian dibentuk dalam format popup, sehingga tampilan buku menjadi 3 dimensi dan menarik pembaca.

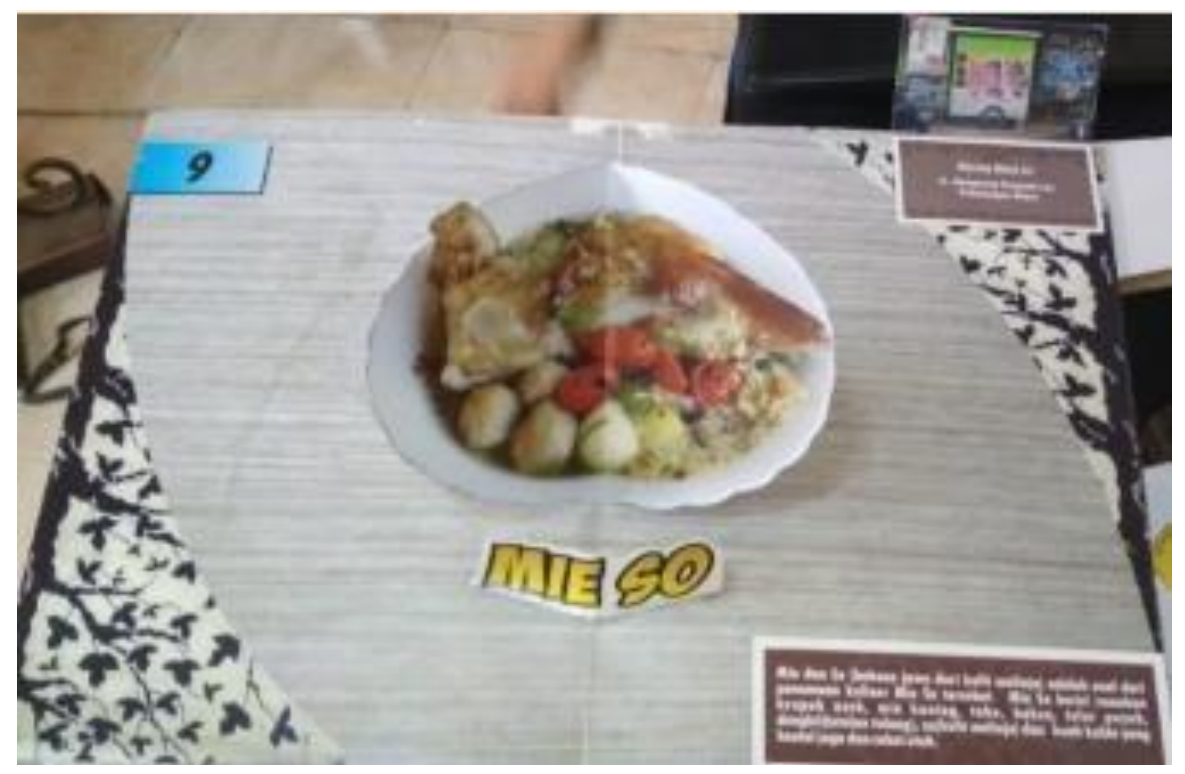

Gambar 15 Contoh tampilan Pop-up

\section{SIMPULAN DAN SARAN}

Di Kota Pekalongan terdapat banyak wisata kuliner yang perlu dikenalkan kepada masyarakat luas. Sesuai penelitian yang telah peneliti lakukan, dari 9 lokasi wisata kuliner di Kota Pekalongan, 10\% menggunakan radio sebagai media promosi, 20\% menggunakan tv swasta, $10 \%$ menggunakan sosial media dan $60 \%$ menggunakan media apapun untuk mempromosikan kulinernya. Oleh karena itu, peneliti memberikan alternatif pengenalan dan promosi wisata kuliner yaitu dengan menggunakan Buku Pop-Up Jelajah Kuliner Kota Pekalongan.

Produk dari penelitian ini menjadi rekomendasi bagi pemerintah Kota Pekalongan untuk terus melakukan pengenalan dan promosi kuliner khas Pekalongan. Buku Pop-Up 
"Jelajah Kuliner Kota Pekalongan" dapat dijadikan media pembelajaran di sekolah untuk mengenalkan kuliner Kota Pekalongan. Selain itu, buku pop-up ini dapat dijadikan media promosi kuliner melalui pameran yang diselenggarkan baik di Kota Pekalongan maupun di luar Kota Pekalongan. Pemakaian gambar dan informasi pada buku ini harus dengan ijin penulis, mengingat produk dari penelitian ini merupakan kekayaan intelektual yang didaftarkan pada HAKI (Hak atas Kekayaan Intelektual).

Berdasarkan hasil dari penelitian ini, peneliti memberikan saran kepada pemerintah Kota Pekalongan untuk terus melakukan upaya peningkatan ekonomi masyarakat Kota Pekalongan melalui promosi wisata kuliner.

\section{DAFTAR PUSTAKA}

Dzuanda. 2011. Design Popup Child Book Puppet Figures Series? Gatotkaca?. JurnalLibrary ITS Undergraduate, (Online), (http; //library,its.undergraduate,ac.id, diakses pada 10 Oktober 2015).

Joko Muktiono. 2003. Menumbuhkan Minat Baca Pada Anak. Jakarta: PT. ElexMedia Komputindo.

Pramitasari, A. Aulia, Hanindya. Widadi, Zahir. 2015. Pengembangan Buku Pop- up Pekalongan sebagai Media Edumotik (Edukasi dan Promosi Batik) Kota Pekalongan. Jarlitbang Kota Pekalongan. Volume (8)

Sugiyono. 2016. Metode Penelitian \& Pengembangan (Research and Development. Bandung. Alfabeta

Zulmi, Muhammad Nizar, Nugroho, Ilham, Salsabila, Dewi. 2018. Reaktualisasi Citra Wisata Kabupaten Batang Melalui Pengembangan Pop-Up Visit Batang Heaven of Asia Sebagai Media Edumowisata (Edukasi Promosi Wisata) Kabupaten Batang. Ristek Kabupaten Batang. Volume (3) No. 1 